\title{
Dissuasão, redução de armas nucleares e defesas antimísseis nos governos Bush e Obama
}

\author{
Deterrence, reduction of nuclear weapons and missile defense \\ in Bush and Obama administrations
}

DIEGO SANTOS VIEIRA DE JESUS*

Rev. Bras. Polít. Int. 56 (2): 79-93 [2013]

Com o fim da Guerra Fria, os EUA mantiveram um arsenal nuclear substancial para dissuadir potenciais ameaças da Rússia. Eles não descartaram o primeiro uso de armas nucleares em conflitos com outros Estados, como aqueles armados com armas químicas e biológicas. A administração de George W. Bush (2001-2009) enfatizou que os EUA e a Rússia não eram mais inimigos e que os EUA não mais planejariam ou dimensionariam sua força nuclear a fim de dissuadir uma ameaça russa. Os EUA manteriam um arsenal nuclear para responder a capacidades de qualquer adversário potencial, focando na forma como lutariam em vez de contra quem lutariam. Ademais, os EUA combinariam as armas nucleares com defesas antimísseis, armas convencionais e uma infraestrutura responsiva na busca de oferecer garantias aos aliados norte-americanos, persuadir os adversários dos EUA a não atacar, dissuadir o conflito e derrotar adversários se o conflito ocorresse. A administração Bush anunciou que os EUA reduziriam o número de ogivas nucleares operacionalmente desdobradas, mas que não eliminariam muitos vetores enquanto reduzissem sua força e manteriam ogivas não desdobradas armazenadas como uma força responsiva que poderia ser adicionada às forças desdobradas (Woolf 2006).

O presidente Barack Obama - cuja administração se iniciou em 2009 - deu destaque, em seu discurso em Praga em abril daquele mesmo ano, à sua estratégia para o avanço na direção de um mundo livre de armas nucleares. Ele destacou que colocaria um fim no pensamento da época da Guerra Fria ao reduzir o papel das armas nucleares na estratégia norte-americana de segurança nacional e renovar as negociações com a Rússia para mais reduçôes verificáveis nas reservas dos dois Estados. Em abril de 2010, a administração Obama completou sua Revisão da Postura Nuclear - Nuclear Posture Review (NPR) -, que definiu passos para a

\footnotetext{
* Diego Santos Vieira de Jesus é professor do Instituto de Relações Internacionais (IRI) da Pontifícia Universidade Católica do Rio de Janeiro (PUC-Rio), Rio de Janeiro, Brasil (dsvj1408@terra.com.br).
} 
redução do papel e do número das armas nucleares norte-americanas e enfatizou que o papel fundamental das forças nucleares norte-americanas era dissuadir ataques nucleares contra os EUA e seus aliados e parceiros. No mesmo mês, Obama e o então presidente russo, Dmitry Medvedev, assinaram o Novo Tratado de Redução de Armas Estratégicas - Strategic Arms Reduction Treaty (START) -, que requereu reduções verificáveis das ogivas estratégicas desdobradas dos EUA e da Rússia ao nível de 1.550 ogivas para cada Estado até 2018. Obama declarou que, depois do Novo START, sua administração buscaria mais negociações com a Rússia para a redução de ogivas não desdobradas e ogivas não estratégicas e seus vetores associados (Drell e Goodby 2012). Entretanto, a assinatura do Novo START veio acompanhada de um compromisso multibilionário de novos recursos para a pesquisa, o desenvolvimento e a manutenção de armas nucleares nos EUA (Kramer 2010, 24-25). A administração Obama também viu que as defesas antimísseis seriam fundamentais na garantia da segurança norte-americana.

O objetivo do artigo é analisar as perspectivas das administrações Bush e Obama com relação à dissuasão, à redução de armas nucleares e às defesas antimísseis, examinadas nas seções seguintes respectivamente. Sustento que, ainda que houvesse diferenças quanto às formas de implementação de decisões, ambas as administraçôes reafirmaram o papel fundamental das armas nucleares para a dissuasão, comprometeram-se com a redução de armas nucleares acompanhada de iniciativas para modernização e reconheceram a importância de defesas antimísseis na proteção dos EUA e aliados. Tais perspectivas estão relacionadas à necessidade contínua de ampliar a flexibilidade para lidar com ameaças contemporâneas e à manutenção de opções diversificadas para o enfrentamento desses desafios.

\section{A dissuasão nos governos Bush e Obama}

Quando ainda era candidato à presidência da República, George W. Bush dizia que a administração de Bill Clinton (1993-2001) mantinha-se presa a uma "mentalidade da Guerra Fria" e que os EUA precisavam combater as novas ameaças do século 21, de forma que deveriam repensar os requisitos para a dissuasão nuclear. Nos últimos anos da administração Clinton, o Congresso impediu que o presidente reduzisse as forças nucleares estratégicas dos EUA abaixo dos níveis especificados no START I até que o START II, de 1993, entrasse em vigor. O Senado declarou que o presidente seguinte somente poderia reduzir as forças norte-americanas depois de conduzir uma nova NPR, que foi enviada como um relatório confidencial ao Congresso no fim de dezembro de 2001 pela administração Bush (Woolf 2006, 1-3).

A administração Bush declarou que as forças nucleares continuavam a ter um papel relevante na defesa dos EUA e de seus aliados e amigos. Elas ofereciam capacidades plausíveis para dissuadir um amplo conjunto de ameaças, incluindo armas de destruição em massa e forças militares convencionais de grande escala. 
Porém, os EUA não mais planejariam, dimensionariam ou manteriam suas forças nucleares como se a Rússia fosse uma versão menor da ameaça trazida pela extinta URSS. A administração Bush reconhecia que, no futuro, os EUA provavelmente seriam desafiados por adversários que teriam um grande conjunto de capacidades - até mesmo perspectivas assimétricas de empreendimento da guerra, como armas de destruição em massa - e poderiam ameaçar os interesses e os aliados dos EUA, as forças que protegiam os interesses norte-americanos e o território de tal Estado a fim de chantagear os EUA a abandonarem seus compromissos ao redor do mundo. A administração Bush enfatizou que as armas nucleares continuavam a ser as únicas no arsenal dos EUA que poderiam manter sob risco o amplo conjunto de alvos valorizados por um adversário, de forma que continuavam a ter um papel fundamental na estratégia de dissuasão dos EUA. Porém, enfatizou que as armas nucleares, em conjunto com as defesas antimísseis e outros elementos das capacidades militares dos EUA, não apenas dissuadiriam adversários, mas garantiriam a aliados e amigos o comprometimento dos EUA com a sua segurança ao oferecerem uma capacidade dissuasiva estendida; persuadiriam os adversários potenciais a não desafiarem os EUA com armas nucleares ou outras ameaças assimétricas; e derrotariam inimigos ao manterem em risco os alvos que poderiam não ser destruídos por outros tipos de armas (Kristensen 2005; Woolf 2006, 4-9).

Além de ampliar o papel das armas nucleares para além da dissuasão, a administração Bush alterou o papel da dissuasão na estratégia de segurança nacional dos EUA. Os EUA poderiam não ser capazes de conter ou dissuadir os tipos de ameaças que emergiam na contemporaneidade, como as representadas por Estadospárias ou organizações terroristas armados com armas de destruição em massa. Assim, os EUA também deveriam estar preparados para realizar a preempção dessas ameaças ao lançarem ataques contra adversários antes que estes atacassem os EUA, seus aliados ou seus interesses. Alguns analistas concluíram que a administração previa o possível uso preemptivo das armas nucleares contra Estados ou grupos que não necessariamente tivessem suas próprias armas nucleares. A administração Bush garantia que, apesar de contribuírem para objetivos distintos, as armas nucleares teriam um papel menor na estratégia de segurança nacional dos EUA no futuro do que na época da Guerra Fria: os EUA buscariam dissuadir e derrotar adversários com armas convencionais de precisão, que poderiam destruir alguns alvos que eram destinados às armas nucleares no passado, e defesas antimísseis balísticos, que poderiam dissuadir o ataque ao negar aos adversários a habilidade de ameaçar os alvos norte-americanos com mísseis balísticos. Alguns especialistas defenderam que um conceito de segurança nacional que combinasse capacidades nucleares e convencionais apagaria a distinção entre os dois tipos de armas e assim ampliaria a probabilidade de uma resposta nuclear. Entretanto, a administração defendia que a presença de opçóes nucleares e convencionais reduziria as pressões para o apelo às armas nucleares ao dar ao presidente opções não nucleares para garantir a segurança dos EUA (Woolf 2006, 9-11; Yost 2005, 91-93). 
Ademais, os EUA não descartaram a possibilidade de primeiro uso das armas nucleares. Embora eles tivessem afirmado que não atacariam, com armas nucleares, Estados não nuclearmente armados, sob a maioria das circunstâncias, eles mantiveram uma política de "ambiguidade estudada" sobre as circunstâncias sob as quais considerariam a retaliação nuclear e o tipo de resposta que poderiam utilizar se um Estado atacasse os EUA com armas de destruição em massa. $\mathrm{Na}$ NPR, a administração Bush parecia adotar uma perspectiva mais explícita que as administraçóes anteriores quanto ao uso de armas nucleares, ao reconhecer que os EUA poderiam utilizar armas nucleares em resposta a ataques empreendidos por Estados que tinham armas químicas, biológicas ou convencionais. Em 2004 e 2005, foram listadas algumas circunstâncias sob as quais os EUA poderiam considerar o primeiro uso de armas nucleares: as armas nucleares poderiam ser utilizadas não apenas em resposta ao uso de armas nucleares, químicas e biológicas por outros Estados, mas em antecipação a esse uso para destruir instalações que pudessem armazenar tais armas e demonstrar a capacidade dos EUA de usar armas nucleares para dissuadir o uso de armas de destruição em massa por adversários. Contudo, alguns analistas defendiam que os planos para o possível uso de armas nucleares contra Estados não nuclearmente armados eram incompatíveis com as garantias negativas de segurança oferecidas aos Estados não nuclearmente armados sob o Tratado de Não Proliferação de Armas Nucleares (TNP). A administração Bush apontou tipos de contingências para os quais acreditava que os EUA deveriam se preparar para lidar fazendo uso de planos de emprego de armas nucleares. As contingências imediatas incluíam perigos correntes e bem reconhecidos, como um ataque com armas de destruição em massa sobre as forças ou os aliados norteamericanos no Oriente Médio ou na Ásia. As contingências potenciais eram perigos plausíveis, mas não imediatos, como a emergência de novas coalizões militares adversárias ou a reemergência de um competidor de capacidades semelhantes, enquanto as contingências inesperadas eram desafios de segurança não previstos, o que poderia incluir uma mudança repentina de regime pela qual um arsenal nuclear existente fosse transferido para o controle de uma liderança hostil ou uma repentina aquisição de armas de destruição em massa por um adversário. $\mathrm{O}$ foco no inesperado destacava a insistência da administração de que os EUA desenvolveriam e expandiriam suas capacidades para o "planejamento adaptativo". Cumpre também lembrar que, de acordo com a administração, o desenvolvimento de novos tipos de armas nucleares que pudessem derrotar alvos enterrados profundamente e o uso potencial de armas nucleares em retaliação por ataques não nucleares seriam uma parte dos esforços dos EUA de persuadir outros Estados a não adquirirem e ameaçarem o uso de armas químicas, biológicas ou nucleares (Payne 2005, 136-145; Woolf 2006, 12-25; Yost 2005, 93-94).

Em 2008, o então senador e candidato à presidência da República Barack Obama definiu seus planos de desarmamento caso fosse eleito. Ele afirmou que estabeleceria uma nova direção na política para armas nucleares e mostraria ao 
mundo que os EUA acreditavam no seu compromisso sob o TNP de trabalhar para a eliminação de todas as armas nucleares. Tendo tornado claro que os EUA não se desarmariam unilateralmente, ele destacou que os EUA manteriam uma capacidade nuclear dissuasiva forte, segura e confiável enquanto outros Estados mantivessem suas armas nucleares. Obama ressaltou que não autorizaria o desenvolvimento de novas armas nucleares e tornaria o objetivo de eliminação das armas nucleares ao redor do mundo um elemento central da política nuclear norte-americana. Obama demonstrou seu compromisso com a perspectiva de desarmamento total e dissuasão continuada, que se refletiu proeminentemente na NPR de abril de 2010 e na Estratégia de Segurança Nacional de maio de 2010. Ambas enfatizaram o compromisso dos EUA de deixar para trás a confiança nas armas nucleares e a necessidade crescente de dissuadir inimigos e oferecer garantias a aliados e parceiros (Schachter 2011, 27-28).

Após o período inicial de Obama na presidência, tornou-se claro que o controle de armas não levaria automaticamente ao desarmamento. Ademais, ele almejava reter uma capacidade dissuasiva enquanto as armas nucleares existissem. Entretanto, é possível identificar que a dissuasão apresenta uma série de problemas e limitações. Ela só é plausível se os adversários permanentemente demonstram que podem utilizar as armas nucleares, e o conceito parece somente operar com atores racionais. Ela também requer que os adversários confiem que os outros a respeitem, adiram a tais princípios, comuniquem-se uns com os outros e entendam os sinais dos outros. Ademais, a confiança na dissuasão pode levar à proliferação nuclear e às corridas armamentistas, e a dissuasão pode criar instabilidade e situações perigosas por conta de erros de cálculo, problemas de comunicação e acidentes técnicos. A dissuasão também é cara, porque pode requerer modernização contínua e o desenvolvimento e a produção de novas armas (Gärtner 2012, 4-6).

A administração Obama clamou por reduções graduais no tamanho das forças nucleares e na confiança nessas armas, enquanto enfatizou a necessidade de manter uma dissuasão nuclear efetiva enquanto o desarmamento era atingido. Porém, se um certo número de armas pode levar à dissuasão estável e nenhuma arma ostensivamente torna a dissuasão desnecessária, há um número entre esses pontos em que a dissuasão poderia não mais prevalecer e um primeiro ataque poderia se tornar uma opção atraente por causa da habilidade real e percebida de infligir um ataque nuclear decisivo sobre o outro lado, com o perigo percebido limitado de sofrer retaliação nuclear. O desarmamento total parece ser um slogan vazio embora politicamente valioso -, porque ele potencialmente enfraquece a dissuasão, encoraja o acobertamento de armas e, em último caso, incentiva o primeiro uso de armas nucleares. Ademais, a redução da confiança nas armas nucleares e as novas limitaçôes autoimpostas sobre seu uso, descritas na NPR de 2010, tornam difícil não concluir que os EUA estavam menos determinados a usar as armas nucleares naquele momento do que no passado. Com mensagens ambíguas, a guerra convencional e os erros de cálculo relacionados às armas nucleares, bem como uma 
maior proliferação nuclear, podem se tornar mais prováveis. Como muitos aliados dos EUA confiam nas armas nucleares norte-americanas para sua própria proteção, a percepção da hesitação norte-americana quanto ao uso de armas nucleares pode encorajar Estados inimigos, o que, por sua vez, seria capaz de levar tais aliados a desenvolver sua própria capacidade nuclear (Schachter 2011, 30-31).

A NPR de 2010 declara que os EUA não usariam ou ameaçariam usar as armas nucleares contra Estados não nuclearmente armados que fossem partes do TNP e mantivessem o compromisso com suas obrigações de não proliferação nuclear. O mesmo documento aponta que os EUA viam o Irã e a Coreia do Norte como Estados que não cumpriam suas obrigações perante o TNP. O documento parecia sugerir que os EUA poderiam usar ou ameaçar o uso de armas nucleares contra um Estado não nuclearmente armado, mas que estivesse em vias de adquirir armas nucleares, como muitos acreditavam que o Irã pudesse ser. Esse ponto da NPR parece buscar persuadir Estados não nuclearmente armados que são partes do TNP a trabalhar com os EUA e outras partes interessadas na adoção de medidas efetivas para fortalecer o regime de não proliferação. Apesar de poderosa, tal mensagem poderia ser entendida como um elemento que reforçava a lógica de aquisição de armas nucleares, uma vez que parecia que a única forma de se evitar uma imposição norte-americana seria dissuadir os EUA com armas nucleares. Além disso, no caso de outros Estados, a NPR indicava que permanecia um estreito conjunto de contingências nas quais as armas nucleares dos EUA ainda poderiam ter um papel na dissuasão de um ataque convencional ou químico/biológico contra os EUA e seus aliados ou parceiros. Assim, os EUA não estavam preparados, naquele momento, para adotar uma política universal de que o único propósito das armas nucleares dos EUA fosse dissuadir o ataque nuclear contra os EUA e seus aliados, mas trabalhariam para estabelecer as condições sob as quais tal política pudesse ser adotada de forma segura (Schachter 2011, 32-34).

\section{A redução de armas nucleares nos governos Bush e Obama}

A administração Bush anunciou que os EUA reduziriam suas forças nucleares estratégicas a 1.700-2.200 ogivas operacionalmente desdobradas ao longo da década. Novas reduções foram codificadas no Tratado sobre Reduções Ofensivas Estratégicas - Strategic Offensive Reductions Treaty (SORT) -, assinado pelos EUA e pela Rússia em maio de 2002. As ogivas operacionalmente desdobradas estariam disponíveis imediatamente ou em questão de dias a fim de fazer frente às contingências imediatas ou inesperadas. A administração Bush defendia que o tamanho dessa força não era determinado pela necessidade de responder a uma ameaça russa; porém, ela considerou as capacidades nucleares remanescentes da Rússia ao desenvolver a NPR. Um conflito com a Rússia era considerado uma "contingência potencial" que surgiria se a relação entre os EUA e a Rússia se deteriorasse significativamente. As forças necessárias para lidar com as contingências 
potenciais estavam inclusas na força responsiva, não na força operacionalmente desdobrada de ogivas. A administração Bush indicava que os EUA manteriam uma tríade de mísseis balísticos intercontinentais - intercontinental ballistic missiles (ICBMs) -, mísseis balísticos lançados de submarinos - submarine-launched ballistic missiles (SLBMs) -, e bombardeiros pesados para o futuro (Huntley 2006, 51, 64; Woolf 2006, 25-26).

Analistas apontavam que as perspectivas da administração Bush de reduções profundas nas armas nucleares ofensivas eram minadas por seus planos de manter milhares de ogivas armazenadas para a força responsiva. Para a administração Bush, a flexibilidade para restabelecer as ogivas nucleares rapidamente, expandir o número de ogivas desdobradas ao longo do tempo e desenvolver novas armas com novas capacidades tornava possível para os EUA reduzir suas armas desdobradas no curto prazo sem criar riscos potenciais à sua segurança no futuro. Além disso, a administração Bush não abordou questões sobre as armas nucleares não estratégicas dos EUA e da Rússia na NPR. Após a assinatura do SORT, a administração Bush começou a reconhecer que as armas nucleares não estratégicas deveriam estar na agenda de discussões entre os EUA e a Rússia, em especial na agenda do grupo de consulta para estabilidade estratégica, anunciado em maio de 2002 (Huntley 2006, 51-53; Woolf 2006, 46-48).

De acordo com a administração Bush, uma infraestrutura que permitisse aos EUA manterem suas forças e as adaptarem a fim de atenderem às necessidades emergentes ofereceria à grande potência meios de responder a ameaças novas, inesperadas ou emergentes. Ademais, ao manter a infraestrutura necessária à adaptação de antigas ogivas e à produção de novas, os EUA poderiam reduzir suas reservas de ogivas não desdobradas. Tal caracterização da infraestrutura de armas nucleares e sua integração ao novo modelo de dissuasão não alterava suas funções centrais, mas destacava o compromisso da administração com a modernização e a expansão do complexo. A administração Bush indicou que os EUA continuariam a observar a moratória dos testes nucleares, apesar da oposição do presidente Bush ao Tratado de Proibição Completa de Testes Nucleares - Comprehensive Nuclear-Test-Ban Treaty (CTBT). Os EUA continuariam a buscar programas visando à segurança e à confiabilidade das reservas de armas nucleares. Ademais, a administração definiu um programa mais amplo para reconstruir o complexo de armas nucleares e sua força de trabalho. A NPR de 2001 recomendava que a infraestrutura tivesse a capacidade de identificar e reparar problemas nas ogivas existentes e permitir o desenvolvimento e a produção de novos tipos de ogivas. A administração Bush também solicitou ao Congresso que acabasse com a proibição de pesquisas de novas armas nucleares de baixa potência e também buscou financiamento para um estudo sobre uma ogiva nuclear modificada destinada a penetrar o solo antes da explosão, podendo-se ampliar a probabilidade de destruição de alvos enterrados profundamente. A NPR também recomendou que os EUA reduzissem o tempo necessário à retomada de testes nucleares, vendo 
que a ampliação para a prontidão de testes era prudente diante da possibilidade de que um problema relacionado à segurança ou à confiabilidade não fosse corrigido sem testes (Woolf 2006, 37-40).

O que o presidente Barack Obama sugeriu em seu discurso em Praga em 2009 não foi exatamente o desarmamento, mas medidas de controle de armas: um tratado que seguisse o START I - o Novo START -, a ratificação do CTBT e a conclusão de um Tratado de Proibição da Produção de Materiais Físseis - Fissile Material Cutoff Treaty (FMCT) - para armas nucleares ou outros explosivos nucleares (Gärtner 2012, 4-6). Cumpre lembrar que, na Conferência de Exame do TNP de 2010, os Estados se comprometeram a buscar mais reduções de armas nucleares, inclusive de armas não estratégicas; pressionaram pela ratificação do CTBT nos EUA; clamaram pelo início imediato de negociações para o FMCT e instruíram os Estados nuclearmente armados a reduzir a confiança nas forças nucleares para sua segurança nacional. Tais elementos pareciam ter o apoio da administração Obama. Segundo a NPR de 2010, ao modernizar as instalaçōes nucleares e investir em capital humano, os EUA poderiam substancialmente reduzir o número de armas nucleares retidas como uma garantia contra surpresas técnicas ou geopolíticas, acelerar o desmantelamento de ogivas removidas de serviço e melhorar o entendimento das atividades estrangeiras relacionadas às armas nucleares. A NPR também declarava que as ogivas nucleares dos EUA nunca seriam usadas contra Estados não nuclearmente armados que mantivessem o compromisso com o TNP, mesmo se tal Estado usasse uma arma química ou biológica. Nesse caso, a revisão propõe uma resposta militar convencional devastadora. Porém, a revisão de Obama desapontou alguns defensores do desarmamento nuclear ao não banir o primeiro uso de armas nucleares em um conflito com outros Estados nuclearmente armados. $\mathrm{O}$ documento cita um conjunto estreito de contingências em que uma ameaça plausível de um ataque nuclear norte-americano era necessário para dissuadir um ataque convencional, químico ou biológico contra os EUA ou seus aliados (Kramer 2010, 26).

Autores como Lieber e Press (2011) defendiam que os EUA provavelmente enfrentariam desafios maiores relacionados à dissuasão nos próximos anos em relação àqueles enfrentados durante a Guerra Fria. Conforme houvesse a proliferação de armas nucleares, tornava-se provável que os EUA se encontrassem em conflitos convencionais com adversários nuclearmente armados. Ademais, os autores acreditavam que manter uma combinação correta de capacidades no arsenal nuclear dos EUA seria vital para dissuadir ou responder a adversários que se engajassem numa escalada nuclear coerciva. A fundação de uma capacidade dissuasiva plausível era a manutenção da capacidade e da determinação de empreender ameaças. Entretanto, a maioria das armas nucleares no arsenal dos EUA, até mesmo os mísseis balísticos baseados em terra e em submarinos, tinha enormes potências explosivas, de forma que usá-las espalharia radioatividade ao longo de vastas regiōes e certamente mataria um número grande de não combatentes. A ameaça 
de uso indiscriminado de armas não seria plausível, e, para reter uma capacidade dissuasiva plausível, os EUA deveriam ter armas nucleares que um líder pudesse realmente usar se os aliados, as forças militares ou o território dos EUA sofressem um ataque nuclear (Lieber e Press 2011).

A administração Obama definiu uma perspectiva pragmática para o arsenal nuclear dos EUA, que trazia dois objetivos principais: a redução do tamanho do arsenal nuclear dos EUA e a manutenção de uma capacidade dissuasiva robusta. $\mathrm{Na}$ direção do primeiro objetivo, a administração Obama negociou e garantiu a ratificação do Novo START, além de cogitar uma nova rodada de negociações para reduçôes ainda maiores do arsenal. Ao mesmo tempo, propôs um grande esforço de modernização para revitalizar a força restante. Tais propostas incluíam o financiamento da infraestrutura nuclear (o complexo de laboratórios nacionais, instalações de produção e pessoal), a extensão da vida dos sistemas mais antigos e a substituição dos antigos vetores. A administração desejava reter e modernizar as opçôes nucleares de baixa potência, em particular as bombas e os mísseis de cruzeiro lançados por avióes; planejava a construção de uma nova geração de submarinos que lançariam mísseis balísticos; e, segundo especialistas, cogitava o aumento da precisão dos mísseis nesses submarinos (Lieber e Press 2011).

Os proponentes da eliminação das armas nucleares - especialistas da área de controle de armas e seus aliados no Congresso - afirmaram que a promessa de Obama de reduzir o papel das armas nucleares na estratégia de segurança nacional entrava em contradição com seus planos de modernizar a força norte-americana. Tais planos, na visão desses atores, criarão novas capacidades nucleares e tornarão as armas nucleares mais utilizáveis. Entre os moderados e os conservadores no Congresso, o apoio político à modernização nuclear pode ser erodido conforme os congressistas confrontam restriçóes orçamentárias cada vez mais difíceis. No próprio orçamento de defesa, haverá pressão para que seja priorizada a compra de armas que contribuam diretamente para as operaçôes militares correntes, como a contrainsurgência e o contraterrorismo, em relação à tarefa aparentemente menos urgente de modernizar o arsenal nuclear. Embora a Força Aérea tenha restabelecido o foco na missão nuclear após incidentes relacionados ao manejo de ogivas e componentes, sua atenção está mais focada na segurança e na confiabilidade das reservas do que na dissuasão nuclear e nas capacidades militares que a apoiam. Os contratantes da área de defesa perceberam que a dimensão convencional é mais lucrativa que a nuclear (Lieber e Press 2011). A liderança da Força Aérea não explicou de maneira decisiva à população norte-americana por que a dissuasão estratégica manteve-se como uma prioridade de segurança nacional. $\mathrm{O}$ apoio ao arsenal assim foi se esvaindo e dando aos defensores da eliminação das armas nucleares uma chance legítima para alcançarem seus objetivos (Lowther e Kallberg 2013, 2).

O Novo START representava uma ponte possível ligando a era de controle de armas nucleares entre as duas maiores potências nuclearmente armadas aos 
elementos mais urgentes do início do século 21. Esse contexto também era caracterizado pela intenção declarada da Rússia de modernizar suas forças nucleares e convencionais, incluindo reformas drásticas na estrutura de forças convencionais e operações em favor de uma força menor, mais profissional e mais desdobrável. A doutrina militar russa de 2010 preservou os EUA e a Organização do Tratado do Atlântico Norte (OTAN) como possíveis ameaças, mas não tão próximas, e reconheceu que a ameaça de uma guerra de grandes coalizões era menos imediata que aquela representada por guerras locais ou conflitos não convencionais. Porém, não existia um próximo passo óbvio ou incontestável após o Novo START. A administração Obama solicitou ao Departamento de Defesa que considerasse a possibilidade de reduções adicionais abaixo dos níveis do Novo START. Alguns políticos norte-americanos mostram-se cautelosos em revisitar os debates em torno da ratificação do Novo START em qualquer estrutura que seguisse esse tratado (Cimbala 2011, 110-111).

O número de ameaças potenciais aos EUA é maior, uma vez que a Rússia mantém um arsenal comparável ao norte-americano, e a China está expandindo seu arsenal e desenvolvendo tanto novas ogivas como vetores mais avançados. A Coreia do Norte continua um claro adversário capaz de lançar ataques de menor escala contra a Coreia do Sul e ameaça os interesses vitais sul-coreanos e norte-americanos. Contrariamente à visão dominante, há especialistas como Adam Lowther e Jan Kallberg que acreditam que as forças nucleares norte-americanas podem ter sua importância para a segurança nacional ampliada nas próximas décadas. Em face dos cortes em defesa no orçamento por conta dos gastos crescentes com questôes sociais, aqueles que buscam influenciar a política da administração Obama na área nuclear defendem que ataques convencionais de precisão podem substituir as armas nucleares. O que eles não observam é que, em uma era de orçamentos declinantes para defesa, a Força Aérea e a Marinha não podem garantir as capacidades de ataque de precisão requeridas por tais planos. Assim, os EUA novamente confiariam no arsenal nuclear para proteger os interesses vitais do Estado e pouco provavelmente teriam recursos fiscais para construir uma alternativa convencional ao arsenal nuclear (Lowther e Kallberg 2013, 3).

\section{As defesas antimísseis nos governos Bush e Obama}

As defesas antimísseis contribuiriam para a dissuasão, na visão da administração Bush, ao complicarem o planejamento de ataque e minarem a confiança de um adversário que planejasse um ataque com mísseis balísticos. O presidente disse que buscaria o desenvolvimento de tecnologias de defesas antimísseis que poderiam ser desdobradas na terra, no mar e no espaço e protegeriam os EUA, seus aliados e suas forças no exterior dos ataques de mísseis balísticos empreendidos por Estadospárias. Ademais, reconheceu que o sistema planejado de defesas antimísseis não seria compatível com os limites do Tratado sobre Sistemas Antimísseis Balísticos - 
Anti-Ballistic Missile (ABM) Treaty. Bush buscou convencer a Rússia a denunciar o tratado com os EUA, mas, quando tal perspectiva fracassou, ele anunciou, no fim de 2001, que os EUA denunciariam o tratado. A denúncia ocorreu em junho de 2002. Inicialmente, a administração Bush planejava dar continuidade aos programas de defesas antimísseis para teatros de operações - que tentariam interceptar mísseis de menor alcance - e de defesas nacionais antimísseis - que buscariam derrubar mísseis de maior alcance - da época da administração Clinton. Porém, ela eliminou a distinção entre defesas nacionais antimísseis e defesas antimísseis para teatros de operaçōes, dividiu os programas em fases de lançamento, meio curso e terminal e buscou um programa robusto de pesquisa e desenvolvimento a fim de identificar tecnologias e sistemas promissores. A administração e outros que apoiavam as defesas antimísseis apontavam que tais sistemas eram necessários, pois os EUA enfrentavam uma ameaça crescente de Estados que tinham mísseis balísticos e armas de destruição em massa. Em 2004, o Departamento de Defesa começou a desdobrar mísseis de interceptação para seu sistema de defesas antimísseis no Alasca - seis no fim de 2004 e dois mais em 2005. Dois mísseis de interceptação também foram desdobrados na Califórnia (Woolf 2006, 24, 33-34; Yost 2005, 94, 96-98).

O desenvolvimento do sistema de defesas antimísseis encontrou fortes críticas dos aliados europeus dos EUA. Eles se queixavam de que a defesa estratégica do território norte-americano seria equivalente a separar a segurança nacional norteamericana daquela do resto dos aliados europeus, defendendo o princípio básico da defesa indivisível do Ocidente. Em face disso, a administração Bush decidiu construir um novo local para as defesas antimísseis, não na costa leste dos EUA de onde poderia defender somente os EUA -, mas na Europa Oriental, de onde poderia defender tanto a Europa como os EUA contra mísseis iranianos. Em 2007, a administração Bush iniciou negociações com a República Tcheca e com a Polônia para desdobrar os elementos das defesas antimísseis. Os dois Estados europeus receberam positivamente o pedido norte-americano, uma vez que viam o desdobramento permanente de forças norte-americanas no seu território como uma garantia de sua segurança em relação à Rússia. O presidente russo Vladimir Putin caracterizou o desdobramento das defesas antimísseis na Europa como uma ação que reacendia a Guerra Fria, e a Rússia chegou a ameaçar o desdobramento de mísseis terra-terra contra as localizaçoos das defesas antimísseis se elas fossem posicionadas na Polônia e na República Tcheca e sugeriu que poderia denunciar o Tratado sobre Forças Nucleares de Alcance Intermediário - Intermediate-Range Nuclear Forces Treaty (INF) - de 1987. A Rússia alegava que a localização escolhida para as defesas antimísseis na Europa era direcionada para ela, não para o Irã, em face do desenvolvimento limitado das capacidades iranianas em mísseis. Os russos também alegavam que os interceptores de alta velocidade eram capazes de interceptar mísseis balísticos intercontinentais russos lançados para os EUA a partir de bases russas, reduzindo a capacidade dissuasiva da Rússia (Rubin 2011, 59-60). 
Como abandonar completamente a ideia de desdobramento dos sistemas de defesas antimísseis na Europa não era plausível - em particular diante da insatisfação europeia com o foco de Obama nas questôes domésticas e sua aparente negligência com a Aliança Atlântica -, Obama anunciou em 2009 a intenção de desenvolver sistemas de defesas antimísseis mais modestos que seriam incapazes de ameaçar os mísseis balísticos intercontinentais russos. O novo programa definia que o tamanho do sistema de defesas antimísseis dos EUA desdobrado na costa oeste do Estado seria congelado nos níveis daquele momento e os sistemas comprovados baseados no sistema de defesas táticas da Marinha seriam desdobrados na Europa. $\mathrm{O}$ desdobramento seria implementado em fases ligadas à evolução da ameaça. Interceptores ainda mais avançados capazes de atacar mísseis intercontinentais iranianos direcionados para os EUA poderiam ser desdobrados na Polônia, caso a ameaça se desenvolvesse contra a grande potência. Porém, se a administração Obama desejasse ter os meios de defender os EUA a partir do continente europeu dentro de uma década, ela não teria tempo para examinar a evolução da ameaça; assim, ela deveria começar a construir interceptores novos e mais poderosos naquele momento. $\mathrm{O}$ novo plano foi recebido com entusiasmo nos EUA e na Europa, uma vez que ele permitiria casar a segurança dos EUA com a do Ocidente, garantir o compromisso dos EUA com a Europa Oriental e minimizar os receios da Rússia. Entretanto, os russos exigiram a incorporação de uma proibição de defesas estratégicas no texto do Novo START, que estava sendo negociado na ocasião. Obama, já comprometido com as defesas antimísseis nos EUA e o desdobramento de defesas na Europa, recusou. Os EUA não estavam preparados para concordar com a redução de armas nucleares ligadas a quaisquer limitaçóes sobre as defesas estratégicas. Ao final, chegou-se a um acordo: o texto principal do tratado não conteria qualquer referência às defesas antimísseis, mas os negociadores dos EUA concordaram que ela fosse mencionada no preâmbulo. Na visão da Rússia, ela manteria o direito de se opor caso os EUA implementassem a fase final das defesas antimísseis na Europa ou decidissem fortalecer os sistemas de defesas antimísseis já desdobrados nos EUA ao adicionarem interceptores ou desdobrarem defesas antimísseis em novas localizaçôes no território norte-americano. A interpretação norte-americana era diferente, uma vez que os EUA entendiam que o parágrafo no preâmbulo não comprometia o Estado a qualquer limitação no presente ou no futuro. Entretanto, a satisfação expressa na Rússia seguindo a assinatura do Novo START era evidência de que, para o governo, o parágrafo do preâmbulo ressuscitava o Tratado ABM, ao menos em espírito (Rubin 2011, 60-64).

A questão das defesas antimísseis territoriais na Europa já fora tema central nas discussões preparatórias para a Cúpula da OTAN em Lisboa, em 2010. O objetivo da Cúpula era aprovar uma nova definição de objetivos, políticas e estratégias da Aliança Atlântica em face dos novos desenvolvimentos globais. A questão das defesas antimísseis europeias recebeu atenção especial nas discussões da Cúpula, e muitos resultados foram aceitáveis para a Rússia; o próprio presidente Medvedev 
fora convidado para o encontro. A declaração da Cúpula de Lisboa destacava que as defesas antimísseis se tornariam um pilar das capacidades militares da OTAN, lado a lado com as capacidades convencionais e nucleares, e a Aliança era obrigada a defender as populações e os territórios dos membros europeus contra a ameaça de mísseis balísticos, sem menções às fontes da ameaça. O plano de Obama para as defesas antimísseis formaria o núcleo do sistema de defesas antimísseis na Europa, e a Rússia era convidada a cooperar com a OTAN nessa iniciativa e a integrar seus próprios sistemas de defesas antimísseis com os da OTAN. Tal resultado se insere na política de Obama de engajamento com os aliados europeus dos EUA e a política de aproximação com a Rússia. Os interceptores que defenderão a Europa serão primariamente mísseis não estratégicos com capacidades limitadas e não colocarão uma ameaça aos mísseis balísticos intercontinentais da Rússia. Seguindo o sucesso na Cúpula de Lisboa, Obama procurou persuadir o Senado norte-americano a aprovar o Novo START, uma vez que a linguagem preambular ligava a dissuasão estratégica à defesa estratégica, com a limitação implícita da liberdade de ação norte-americana quanto às defesas antimísseis, e assim motivara intensas críticas de senadores conservadores. Para tentar persuadir os senadores republicanos a ratificar o Novo START, o presidente enviou a eles uma carta afirmando que, enquanto fosse presidente e o Congresso oferecesse as verbas necessárias, os EUA continuariam a desenvolver e desdobrar defesas antimísseis efetivas a fim de proteger os EUA, suas forças desdobradas e seus aliados e parceiros. O Senado aprovou o Novo START em dezembro de 2010, mas ligou tal aprovação à liberdade de ação norte-americana com relação às defesas estratégicas. Na Rússia, essa conexão motivou críticas de autoridades no poder Executivo, de parlamentares e da mídia. Com a aprovação do tratado no Parlamento russo, o Novo START entrou em vigor, mas com interpretaçôes distintas entre os dois Estados sobre as implicaçōes do documento para as defesas estratégicas (Rubin 2011, 65-67).

Tanto Medvedev quanto o então primeiro-ministro e atual presidente russo Vladimir Putin destacaram, em 2010, que qualquer plano de defesas antimísseis europeias pelos EUA e pela OTAN que excluísse a Rússia poderia conduzir a uma corrida armamentista nuclear, incluindo novos desdobramentos de armas nucleares pela Rússia. As objeções russas têm mais a ver com questões políticas do que com a lógica da dissuasão nuclear. A inferioridade das forças convencionais russas em relação à OTAN torna a Rússia mais confiante nas suas forças nucleares para outras missões que não a dissuasão de um primeiro ataque nuclear dos EUA ou da OTAN. A doutrina militar da Rússia permite o primeiro uso de armas nucleares numa guerra convencional que inclua ataques próximos à periferia da Rússia ou no território da Rússia com o potencial de ameaçar seus interesses vitais e sua soberania. A Rússia temia as capacidades da OTAN para missóes convencionais de ataque e a superioridade relativa da Aliança nas tecnologias baseadas na informação para o empreendimento de guerras convencionais. A sensação russa de inferioridade militar convencional convidou seus planejadores militares a preencher a lacuna com 
suas armas nucleares não estratégicas (Cimbala 2011, 111, 114-115). A Rússia confia na dissuasão estratégica como base de sua segurança nacional, uma garantia contra a erosão de sua posição internacional. Nesse sentido, qualquer tentativa dos EUA de desdobrar sistemas de defesas antimísseis pode levantar objeções russas e se tornar ponto focal de tensão entre os dois Estados (Rubin 2011, 56). A percepção de que a Rússia e os EUA têm uma singularidade nas capacidades nucleares estratégicas comparativamente a outras potências carrega peso político para negociadores russos em fóruns internacionais e fortalece seu status militar de grande potência (Cimbala 2011, 115).

\section{Considerações finais}

O objetivo do artigo foi examinar as perspectivas das administrações Bush e Obama quanto à dissuasão, à redução de armas nucleares e às defesas antimísseis. Foi possível observar que, ainda que existissem diferenças quanto às formas de implementação de decisões, tanto a administração Bush como a administração Obama reafirmaram o papel fundamental das armas nucleares para a dissuasão, comprometeram-se com a redução de armas nucleares acompanhada de iniciativas para modernização e reconheceram a importância de defesas antimísseis na proteção dos EUA e aliados. Essas perspectivas relacionam-se à necessidade de ampliar a flexibilidade para lidar com ameaças contemporâneas e à manutenção de um leque de opções para fazer frente a tais ameaças.

\section{Referências bibliográficas}

CIMBALA, Stephen J. (2011). "Matrix of Nonlinearity. Minimum Deterrence, Missile Defenses, and Nuclear Arms Reductions". JFQ, 62: 110-116.

DRELL, Sidney D.; GOODBY, James E. (2012). "Nuclear Deterrence in a Changed World". Arms Control Today, 42 (5). <http://www.armscontrol.org/act/2012_06/Nuclear_Deterrence_ in_a_Changed_World $>$. Acesso em 7 de abril de 2013.

GÄRTNER, Heinz. (2012). "Deterrence and disarmament”. Kurzanalyse, 2 (12): 1-7.

KRAMER, David. (2010). “Obama's nuclear weapon agenda is on multiple rapid tracks". Physics Today, 24-27.

KRISTENSEN, Hans M. (2005). "The role of U.S. nuclear weapons: new doctrine falls short of Bush pledge”. Arms Control Today, 35 (7). <http://www.armscontrol.org/act/2005_09/ Kristensen.asp>. Acesso em 24 de abril de 2013.

LIEBER, Kier A.; PRESS, Daryl G. (2011). “Obama’s Nuclear Upgrade: The Case For Modernizing America’s Nukes”. Foreign Affairs. < http://www.foreignaffairs.com/articles/67973/ keir-a-lieber-and-daryl-g-press/obamas-nuclear-upgrade>. Acesso em 8 de abril de 2013.

LOWTHER, Adam; KALLBERG, Jan. (2013) "Nuclear deterrence in a second Obama term". World Defence Systems, 1-3. 
PAYNE, Keith B. (2005). “The Nuclear Posture Review: setting the record straight”. The Washington Quarterly, 28(3): 135-151.

SCHACHTER, Jonathan (2011). “The Obama Administration: Caught between Disarmament and Deterrence”. In: LANDAU, Emily; MALZ-GINZBURG, Tamar (Ed.) The Obama Vision and Nuclear Disarmament. Tel-Aviv: Institute for National Security Studies, 27-38.

RUBIN, Uzi (2011). "The Missile Defense Program: Tension between the United States and Russia”. In: LANDAU, Emily; MALZ-GINZBURG, Tamar (Ed.) The Obama Vision and Nuclear Disarmament. Tel-Aviv: Institute for National Security Studies, p. 55-70.

WOOLF, Amy F. (2006). U.S. nuclear weapons: changes in policy and force structure. Washington, D.C.: Congressional Research Service, The Library of Congress.

YOST, David S. (2005). "New approaches to deterrence in Britain, France, and the United States". International Affairs, 81(1): 83-114.

Recebido em 28 de abril de 2013 Aprovado em 8 de julho de 2013

\section{Resumo}

O objetivo é analisar as perspectivas das administrações de George W. Bush e Barack Obama com relação à dissuasão, à redução de armas nucleares e às defesas antimísseis. Sustenta-se que ambas as administrações reafirmaram o papel fundamental das armas nucleares para a dissuasão, comprometeram-se com a redução de armas nucleares acompanhada de iniciativas para modernização e reconheceram a importância de defesas antimísseis na proteção dos EUA e de aliados. Tais perspectivas estão relacionadas à necessidade contínua de ampliar a flexibilidade para lidar com ameaças contemporâneas e à manutenção de opções diversificadas para o enfrentamento desses desafios.

Palavras-chave: armas nucleares; defesas antimísseis; dissuasão; EUA.

\section{Abstract}

The aim is to analyze the views of the administrations of George W. Bush and Barack Obama regarding deterrence, the reduction of nuclear weapons and missile defense. It is argued that both administrations reaffirmed the fundamental role of nuclear weapons for deterrence, committed themselves to reducing nuclear weapons with initiatives for modernization and recognized the importance of missile defense to protect the US and its allies. Such views are related to the ongoing need to expand the flexibility to deal with contemporary threats and maintain diverse options for addressing these challenges.

Keywords: nuclear weapons; missile defense; deterrence; US. 